establish written procedures for reporting adverse medical device events that include (1) procedures for timely and effective identification and evaluation of event; (2) a standardized review process and procedure for determining whether events are reportable; (3) procedures to assure the timely submission of complete reports; and (4) a mechanism to assure compliance with documentation and recordkeeping requirements.

"Because interim regulations for reporting have been in place since 1990, most healthcare facilities have already developed a reporting program," said Britton Berek, of the American Society for Healthcare Engineering of the American Hospital Association, who has been monitoring the Safe Medical Device Act closely since 1990.

Berek also noted, "The final rule is very similar to the interim proposed rules, however, some changes will need to be made to the existing program." These changes will include expansion of the reporting criteria to include "user error" and "tightening" of the reporting time frame to be within 10 days of the event. In addition, almost all medical facilities are now included, except physician and dental offices.

FDA regulations and guidance documents are available via the Internet at http://www.fda.gov.

FROM: FDA. Medical device reporting. Federal Register December 11, 1995;60:63578.

\section{OSHA's Occupational Injury Reporting}

OSHA announced that it will begin collecting injury and illness data from 80,000 employers in high-hazard industries. At the same time, OSHA has issued proposed changes to the current procedures for recording and reporting workplace injuries, illnesses, and deaths to simplify the system and to improve future use of the data.

In February 1996, injury and illness report forms were scheduled to be mailed to individual workplaces, requesting data from 1995 . The data will be used to expand on a safety and health pilot program being tested in Maine. Assistant Secretary of Labor for Occupational Safety and Health Administration Joseph A. Dear said, "These steps are an important part of OSHA's reinvention efforts to become a data-driven, results-oriented organization.

On February 2, 1996, OSHA published the proposed revision to the "Recording and Reporting Occupational Injuries and Illnesses” (29 CFR:1904). This revision is expected to simplify the reporting process for employers and to improve the quality and accuracy of the safety and health information available for OSHA. In addition, this revision is expected to increase the use of modern technology, including computers, and improved employee awareness and involvement. OSHA estimates that it will reduce the regulatory burden by $\$ 4.7$ million. OSHA has incorporated comments from labor, industry, trade and professional associations (including infection control and hospital groups), and other governmental agencies into the proposed rule.

Under the proposed revisions, healthcare employers would be required to record all bloodborne pathogen exposure incidents that result in disease. Further, OSHA is proposing that employers record lacerations or puncture wounds, eg, needlesticks. OSHA has asked for comments on whether it is appropriate to record these lacerations or puncture wounds if they do not lead to disease. Concern has been expressed already by the healthcare community regarding a requirement for recording bloodborne "exposure incidents" and the unnecessary duplication for those facilities already collecting this information.

OSHA also is proposing that all TB exposures that result in infection (skin-test conversion) be recorded unless there is evidence of a nonwork exposure, such as household or community contact. This proposal is consistent with OSHA's current enforcement procedures for occupational exposure to TB.

Written comments on the proposal must be received by April 29, 1996, in the Docket Office, Docket No. R-02, Room N2625, US Department of Labor, 200 Constitution Ave NW, Washington DC, 20210; telephone 202-219-7894. The text also is on the Internet at http://www.osha.gov in the "What's New Section."

FROM: Department of Labor: OSHA. Occupational injury and illness recording and reporting requirements. Federal Register February 2, 1996;60:4030-4067.

\section{Molecular Epidemiology Workshop}

The CDC, in collaboration with the National French Academy for Basic Research, will sponsor a 3-day workshop on molecular epidemiology and evolutionary genetics of pathogenic microorganisms on June 17-19, 1996, in Atlanta. The purpose of the workshop is to bring together clinicians, epidemiologists, molecular biologists, and evolutionary geneticists working on infectious disease. Healthcare providers, public health professionals, and laboratory scientists are facing a range of issues in combating infectious diseases. There is a critical need to be able to identify infectious agents rapidly in a manner that allows discrimination of closely related strains and species and to use genetic information for studying evolution, emergence, and spread of the pathogens.

For information about the workshop, contact Dr. Michael Tibayrene, telephone 770-488-4524; fax 770-4884454; e-mail: mdt3ciddpd2.em.cdc..gov.

Additional news items in this issue: OSHA Loses Respirator Case, page 285; New TB Test Approved, page 327.

Additional news items in this issue: OSHA Loses Respirator Case, page 285; Simultaneous Influenza and Pneumococcal Vaccines, page 327; New TB Test Approved, page 327. 